\title{
Um olhar sobre a crueldade na primeira época moderna: o método de execução tupinambá e a tortura pre-mortem durante as guerras de religião na Europa
}

\author{
Maria Berbara ${ }^{7}$ \\ DOI 10.20396/eha.vil4.3383
}

A definição da crueldade torna-se um problema intelectual de primeira ordem no século XVI. As guerras de religião europeias, de um lado, e a expansão colonial, de outro, cobram um número estarrecedor de vítimas nos dois lados do Atlântico. Por mais que seja difícil, por não dizer impossível, quantificar com exatidão números de mortes violentas, estima-se que entre dois e quatro milhões de pessoas tenham perdido a vida, somente na França, entre os anos 1560 e 1590 em consequência das guerras de religião; ${ }^{2}$ nas Américas, o estudo de massacres e genocídios cometidos contra sociedades americanas sugere, similarmente, cifras aterrorizantes para mortes violentas neste mesmo período. ${ }^{3}$ Esses dois eventos centralizaram, na segunda metade do Quinhentos, a produção visual e textual relativa ao tema da crueldade - conceito que, nos séculos anteriores, havia sido tratado de modo apenas marginal por pensadores como Agostinho, Jerônimo e Abelardo. ${ }^{4}$

O que se considera cruel, entretanto, distancia-se notavelmente, na primeira época moderna, de tradições pregressas. Um dos aspectos centrais dessa mudança diz respeito ao que se poderia considerar um processo de relativização da crueldade. Até o século XVI, na tradição cristã ocidental, a percepção da crueldade parece estar invariavelmente relacionada à alteridade: cruéis são os outros povos, as outras religiões, os outros hábitos. Vikings, mongóis, turcos ou pagãos personificam,

\footnotetext{
1 Universidade do Estado do Rio de Janeiro

2 KNECHT, Robert. The French Religious Wars, 1562-1598. Oxford: Osprey Publishing, 2002, p. 86 e 91 apud VILLAMIZAR, Carlos Arturo Salamanca. Religión, política y espectáculo: narrativas del martirio en la primera modernidad. In: Anales del Instituto de Investigaciones Estéticas, XXXVIII, v. 109, 2016, p. 100.

3 Um estudo recente de geógrafos da University College London concluiu que o impacto demográfico do avanço colonial europeu nas Américas foi tão forte que afetou o clima mundial. As mortes em massa foram causadas por guerras, massacres e doenças levadas por europeus às Américas. Os estudiosos estimam que 56 milhões de indígenas tenham morrido por causa da conquista europeia do continente americano. Isso levou ao abandono e subsequente reflorestação de 55 milhões de hectares de terra cultivada, o que diminuiu o CO2 atmosférico entre 1520 e 1610 e, por sua vez, contribuiu para o declínio da temperatura global nos séculos que antecederam a revolução industrial. $\mathrm{Cfr}$. $\mathrm{KOCH}$, Alexander; BRIERLEY, Chris; MASLIN, Mark; LEWIS, Simon. Earth System Impacts of the European Arrival and Great Dying in the Americas after 1492. In: Quaternary Science Reviews, v. 207, 2019, pp.13-36.

4 Para uma interessante e bastante completa história do conceito de crueldade entre Sêneca e o século XVI ver: BARAZ, Daniel. Medieval Cruelty. Changing Perceptions, Late Antiquity to the Early Modern Period. Ithaca e Londres: Cornell University Press, 2003. Baraz (p. 20 segg.) indica que o tema da crueldade, tratado por Sêneca em De clementia, reemerge no século XIII com Tomás de Aquino, primeiro pensador medieval a devotar-lhe um estudo específico (a seção sobre temperança na Suma Teológica).
} 
em diferentes momentos históricos, a encarnação absoluta, incontestável, do outro cruel.

Na primeira época moderna, entretanto, surgem critérios para determinar a existência de crueldade. Em situações de guerra ou conflito esses critérios envolvem, por exemplo, o número de vítimas, os métodos, se a crueldade é exercida contra inimigos ou contra o próprio povo, etc. Já não se trata, portanto, de povos cruéis ou não cruéis; uns podem ser mais cruéis que outros, e o outro pode ser menos cruel que o mesmo.

As guerras de religião e a expansão colonial europeia alimentam uma teia comparativa global de escalas e modalidades da crueldade. Em seu livro sobre o conceito de crueldade entre Sêneca e a primeira época moderna, por exemplo, Daniel Baraz examina dois famosos exemplos de martirológios protestantes - o Book of Martyrs de John Foxe e a Histoire des Martyrs de Jean Crespin - nos quais os autores empregam uma lógica silogística para imputar crueldade às perseguições contemporâneas a protestantes: se turcos ou pagãos cometeram terríveis atos de crueldade contra cristãos, e se perseguidores católicos cometeram atos análogos, ergo perseguidores católicos são terrivelmente cruéis.

Em tratados e panfletos, a crueldade dos conquistadores cometida contra sociedades americanas surge como figura e arma retórica no âmbito das guerras de religião entre católicos e protestantes. A ideia de comparar a crueldade cometida por cristãos àquela perpetrada por não cristãos aparece com potente clareza na Brevísima relación de la destruición de las Indias de Bartolomé de Las Casas, na qual o frade dominicano famosamente reporta as atrocidades cometidas por espanhóis nas Américas contra populações indígenas. Depois de descrevê-las com dolorosa viveza de detaIhes, Las Casas observa: "Considere-se agora, por Deus, pelos que lerem isto, se essas obras não excedem toda a crueldade e injustiça que possa ser pensada, e, se vos parece por bem, a tais cristãos chamai-os diabos, e [considerai] se não seria melhor encomendar os índios aos diabos do inferno do que aos cristãos das Índias". ${ }^{5}$ Las Casas, em seu texto, não apenas considera as ações de espanhóis cruéis, mas as piores que se possa imaginar tanto na terra quanto no inferno.

Em sua edição ilustrada da Brevísima, publicada quase cinquenta anos depois da aparição do texto original, o editor protestante Theodor de Bry reforça visualmente o sistema de analogias destinado a equiparar os espanhóis ao tradicional "outro" cruel do cristianismo. Em uma das gravuras, soldados são representados assando um nobre de La Española sobre uma grelha de madeira,

5 Ver a edição da Biblioteca Digital Aberta disponível online: CASAS, Bartolomé de las. Brevísima Relación de la Destrucción de las Indias. Alayor: textos.info, 2016, p. 82. Disponível em: https:/www.textos.info/fray-bartolome-de-las-casas/brevisima-relacion-de-la-destruccion-de-las-indias/descargar-pdf. Acesso em: 24 abr. 2020. O texto original de Las Casas foi publicado na Espanha (Sevilha) em 1552. 
em uma clara referência ao martírio de São Lourenço [Figura 1]; em outra, chicoteiam um homem que haviam escravizado e forçado a trabalhar nas minas, aludindo, dessa vez, à flagelação de Cristo [Figura 2].

Sistemas visuais analógicos, que paralelizavam a crueldade de católicos ou protestantes - dependendo do lado em que se estivesse - aos algozes dos primeiros mártires aparecem com frequência na Europa a partir de meados do século XVI. Uma das ilustrações do livro Ecclesiae Anglicanae Trophaea - uma história do martírio de católicos na Inglaterra desde os primeiros séculos depois de Cristo até 1583 - por exemplo, representa soldados arqueologicamente vestidos como antigos romanos desmembrando, eviscerando e cozinhando membros dos jesuítas Alexander Briant, Ralph Sherwin e Edmund Campion [Figura 3].

Os jesuítas haviam sido condenados, por crime de lesa-majestade, ${ }^{6}$ à uma das mais temíveis formas de execução jamais praticadas no Reino Unido: "to be hanged, drawn and quartered", ou seja, o condenado era arrastado, geralmente por um cavalo, até o local de execução, onde era primeiramente enforcado - não até a morte - e, em seguida, eviscerado e desmembrado. A vítima morria, evidentemente, em algum momento do processo, mas, sobretudo na primeira época moderna, carrascos eram instruídos a prolongar ao máximo a sua agonia. A visão segundo a qual, para condenados por crimes mais graves, a morte deve ser a culminação de uma graduação calculada e metódica de sofrimento prevalece não apenas nas ilhas britânicas, mas, também, em outras partes da Europa durante a primeira época moderna. Na França, por exemplo, a morte pela fogueira foi ocasionalmente praticada até o século XVIII. Nos Países Baixos e em partes da Alemanha, a roda despedaçadora representava uma forma comum de execução prolongada [Figura 4]. ${ }^{7}$

A representação da morte dos jesuítas ingleses estabelece uma série de equivalências visuais entre os seus carrascos e algozes não-cristãos: os soldados, vestidos à antiga maneira romana, cozinham, em primeiro plano, os membros das vítimas, em alusão ao canibalismo tupinambá que, naqueles mesmos anos, era representado ad nauseam nas dezenas de edições dos livros de Jean de Lèry, André Thevet e Hans Staden, entre outros [Figura 5]. Embora não fosse incomum que mem-

\footnotetext{
6 Eles haviam se engajado em uma missão secreta de reconversão da Inglaterra anglicana ao catolicismo, crime que, por ser considerado um atentado à própria figura da rainha, recebeu esta severíssima sentença. Os jesuítas foram executados em Tyburn (Londres) no dia 1 de dezembro de 1581. O seu processo de julgamento e execução foi fartamente documentado em atas e cartas escritas, inclusive, pelos próprios jesuítas. Cfr., por exemplo: KILROY, Gerard. Edmund Campion. A Scholarly Life. Farnham: Ashgate, 2015.

7 Embora seu principal foco de interesse esteja nas mudanças em sistemas penais e punitivos ocorridos a partir do século XVIII, sempre é importante recordar o clássico livro de Michel Foucault Vigiar e Punir (Surveiller et Punir: Naissance de la Prison, publicado originalmente em Paris pela Gallimard em 1975). Sobre a pena capital como espetáculo na primeira época moderna, cfr.: SPIERENBURG, Pieter. The Body and the State: Early Modern Europe. In: MORRIS, Norval Morris; ROTHMAN, David ]. (orgs.). The Oxford History of the Prison: The Practice of Punishment in Western Society. Oxford University Press: 1995, pp. 49-77.
} 

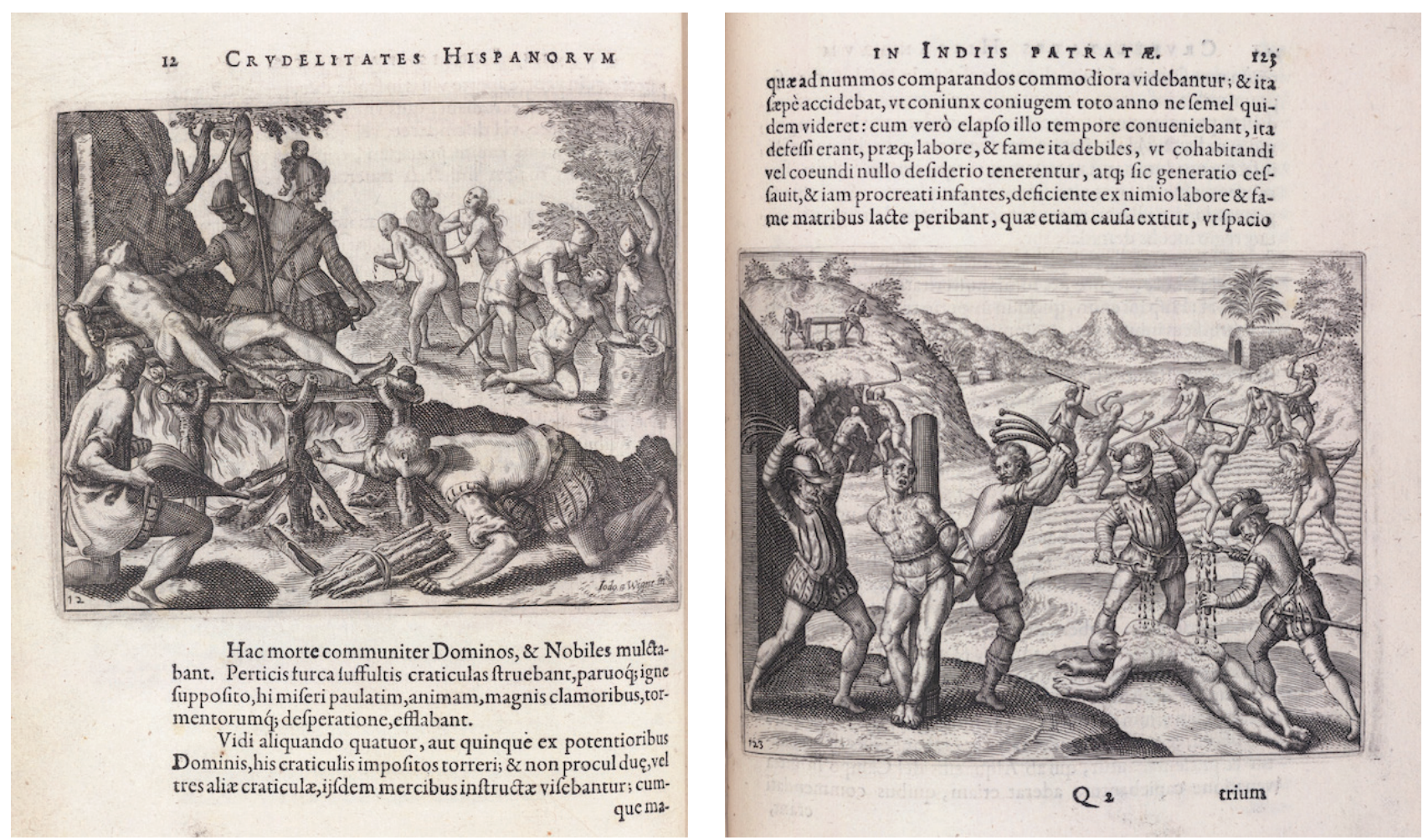

[Figuras 1 e 2] Ilustrações.

In: Brevísima relación de la destruición de las Indias de Bartolomé de Las Casas, de Bartolomé de Las Casas. Edição de Theodor de Bry. Frankfurt, 1598.

[Figura 3]

Giovanni Battista Cavalieri, a partir de Pomarancio (Niccolò Circignani): Martírio dos jesuítas Campion, Sherwin e Briant.

In: Ecclesiae Anglicanae Trophaea. Roma: Bartolomeo Grassi, 1584.

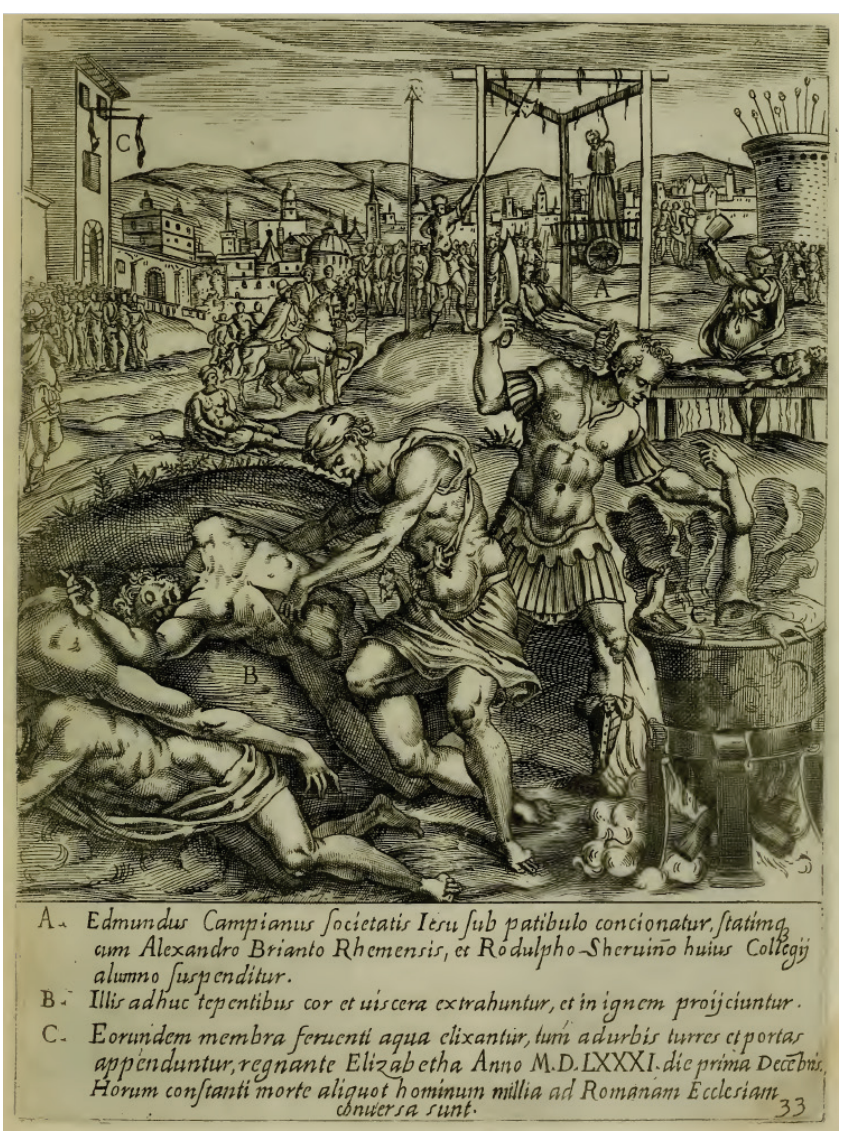


bros dos corpos de executados por crimes de lesa majestade - caso dos jesuítas ingleses - fossem ligeiramente cozidos em água salgada a fim de prolongar a sua preservação e exposição, este era um processo levado a cabo no interior das prisões, e não, como mostra a gravura, em público. ${ }^{8} \mathrm{O}$ fato de que a imagem tenha sido editada de modo a lançar ao seu primeiro plano o caldeirão fervendo com os membros dos jesuítas revela a intenção de criar uma analogia visual cuidadosamente desenhada para comparar a crueldade dos verdugos à dos romanos que executaram os primeiros mártires cristãos e, simultaneamente, dos selvagens canibais americanos.

As reflexões mais diretas sobre a crueldade produzidas na segunda metade do século XVI são, provavelmente, aquelas formuladas por dois pensadores franceses que travaram contato com os Tupinambá: Jean de Lèry e Michel de Montaigne.

Lèry fez parte da segunda expedição francesa ao atual Rio de Janeiro em meados do século XVI. Liderada pelo almirante Nicolas Durand de Villegagnon e financiada pelo rei Henrique II, a empresa colonial pretendia fundar e consolidar a França Antártica, isso é, ocupação colonial francesa em território que, segundo o tratado de Tordesilhas, firmado em 1494 e sancionado pelo papa Júlio II em 1506, pertencia exclusivamente a Portugal. Lèry, que no momento de sua chegada à baía de Guanabara, em 1557, contava com apenas 23 anos de idade, entraria em direta colisão espiritual e ideológica com Villegagnon. Enquanto o almirante mantinha-se fiel às práticas e dogmas centrais defendidos pelo catolicismo, Lèry, que posteriormente seria ordenado ministro calvinista, questionava essas mesmas práticas e dogmas - em especial o dogma da transubstanciação, de acordo com o qual o vinho e a hóstia transformam-se realmente, e não apenas simbolicamente, no sangue e corpo de Cristo durante a eucaristia. ${ }^{9}$

Mais de duas décadas depois de seu regresso, já ministro ordenado, Lèry publicou um livro relatando suas experiências na França Antártica. ${ }^{10}$ Seus capítulos descrevem plantas e animais que o francês havia encontrado na região, assim como as práticas e costumes dos Tupinambá, que, na-

8 Ver: BELLAMY, John. The Tudor Law of Treason. Nova York: Routledge 1979, capítulo 5.

9 Este debate, que, atualmente, pode parecer bizantino, foi a questão teológica mais discutida durante a Reforma. As discussões não se travavam exclusivamente em âmbitos acadêmicos ou clericais, mas, como bem demonstrou Lee Palmer Wandel, fraturavam comunidades europeias em todos os níveis sociais. A violência das guerras de religião não pode ser compreendida independentemente do avançar desses debates teológicos. Cfr.: WANDEL, Lee Palmer. The Eucharist in the Reformation. Incarnation and Liturgy. Cambridge: Cambridge University Press, 2006, p. 2 et seq.

10 O livro, cujo título em português geralmente é abreviado para "Viagem à terra do Brasil", apareceu em 1578 com os tipos de Antoine Chuppin (La Rochelle). A segunda edição, revista e aumentada, foi impressa em Genebra dois anos mais tarde, também por Chuppin. Ainda no Quinhentos seguiram-se três reedições em francês, todas com modificações relativamente à edição que lhes antecedia, em 1585,1594 e 1599 . Também foram produzidas diversas traduções ao latim, a primeira das quais foi impressa em 1586 em Cenebra. O texto latino foi incluído, com novas ilustrações, no terceiro volume das Crandes Viagens de Theodor de Bry (Frankfurt, 1592). No século XVII houve novas edições e traduções (algumas parciais). 


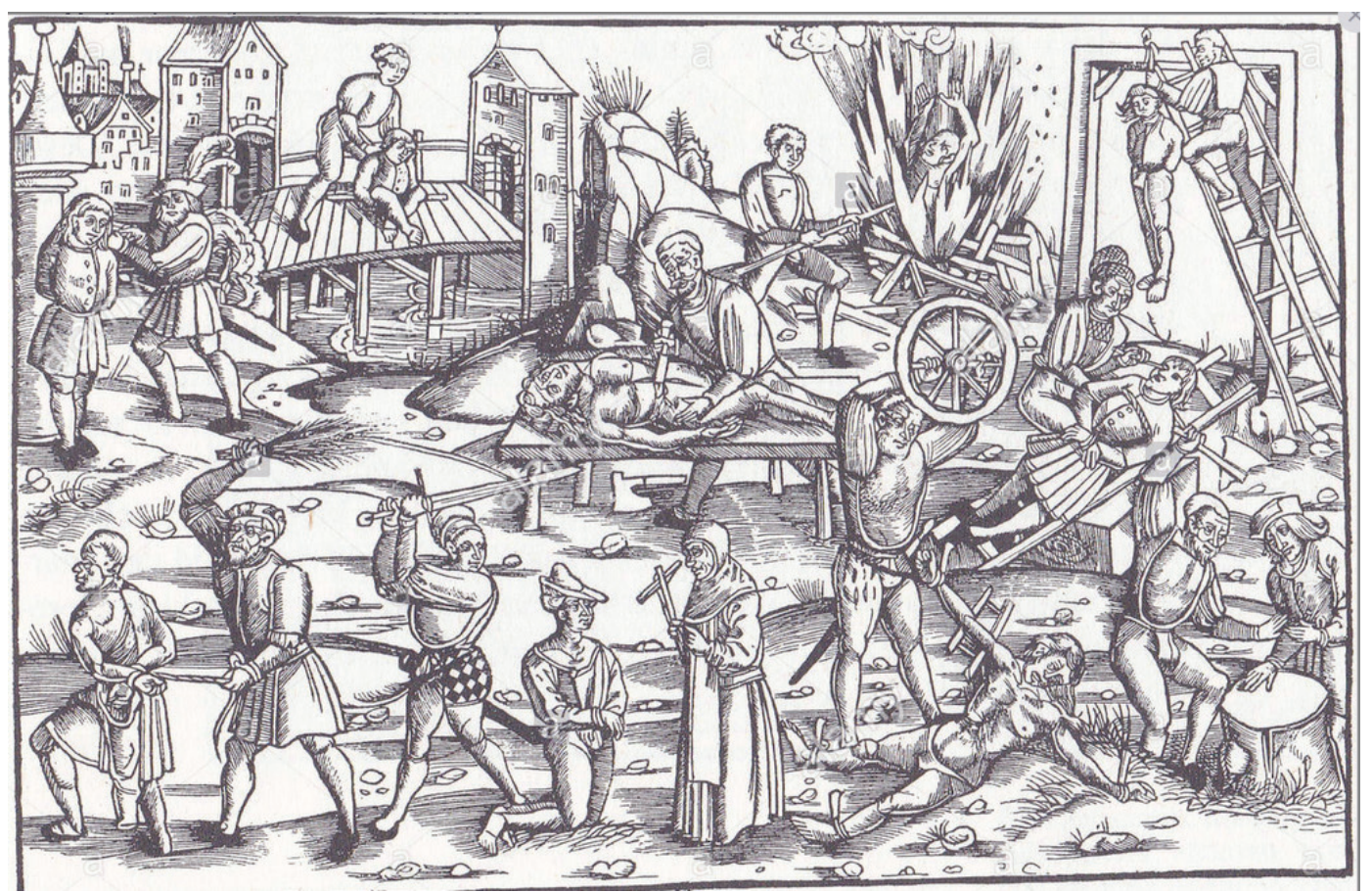

[Figura 4] Ulrich Tengler: Xilogravura representando várias formas de punição. In: Laienspiegel. Augsburg: Hans Othmar, 1509.

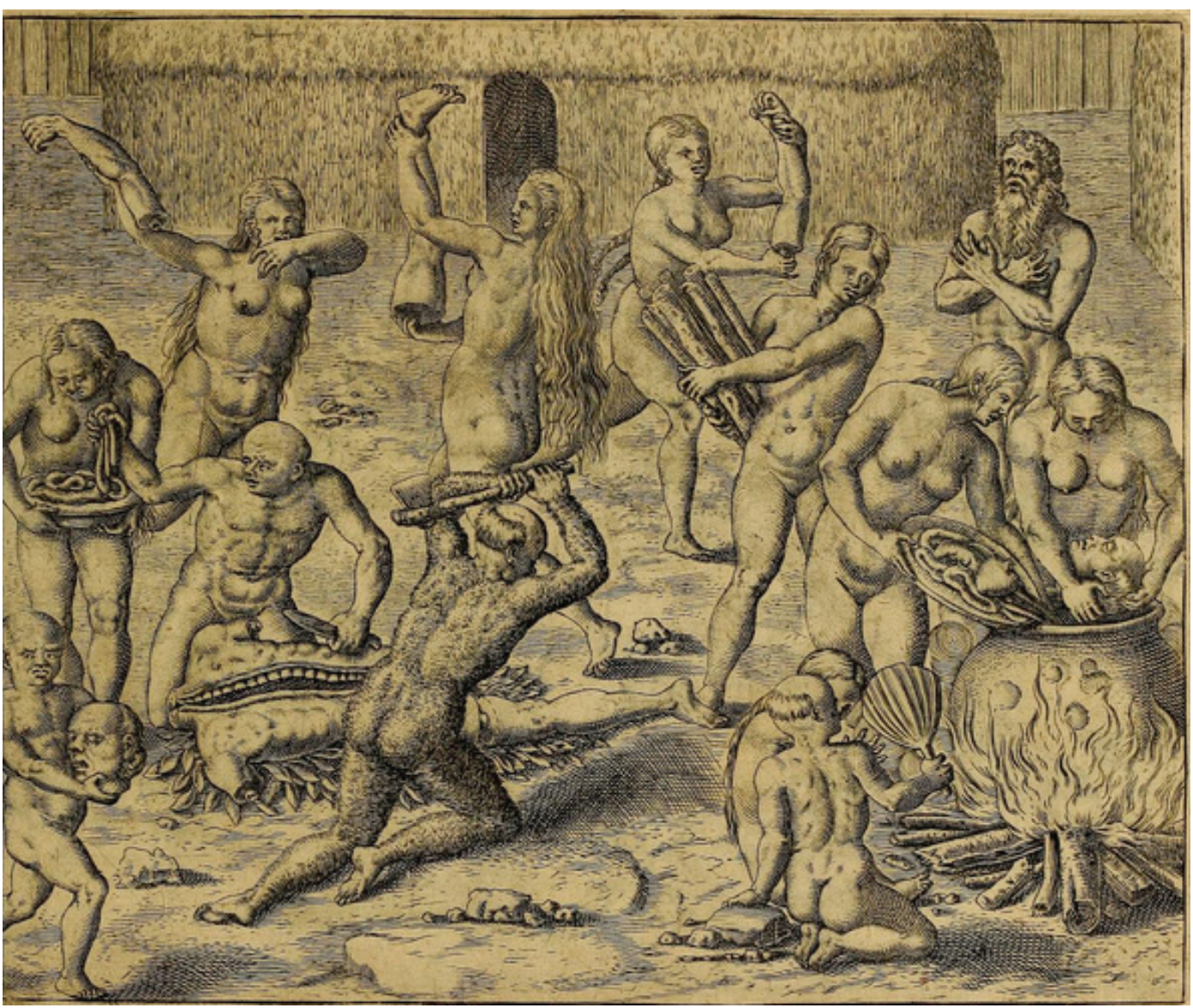

[Figura 5] Theodor de Bry: Hans Staden entre os Tupinambá.

In: Grands Voyages. Frankfurt, 1592, vol. III. 
quele momento, eram aliados dos franceses. No sexto capítulo, o francês expressa, ainda, o que qualifica como comportamento tirânico de Villegagnon, o qual culminaria com a execução, por afogamento, de três colonos que se haviam recusado a proclamar sua crença no milagre da transubstanciação. ${ }^{11}$

Na terceira edição do livro, Lèry expandiu o décimo quinto capítulo - "De como os americanos tratam os prisioneiros de guerra e das cerimônias observadas ao mata-los e devorá-los" - e, na quarta edição (1599), ele o transformou em um apêndice intitulado: "Sobre a crueldade exercida pelos turcos e outros povos, nomeadamente pelos espanhóis, muito mais bárbaros do que os selvagens". Para Lèry, os turcos são mais cruéis que os selvagens do Brasil, pois eles - turcos - são inventivos em seus modos de criar atos de crueldade e deles derivam prazer. Além disso, contrariamente aos "selvagens", as atrocidades que cometem são em grande escala. A crueldade dos católicos, para ele, é a mais abominável. Também é indiscriminada, também ocorre em grande escala, pratica o canibalismo, e, o que é mais grave, volta-se contra seus próprios compatriotas cristãos. Dentro dessa categoria - católicos - os piores de todos, enfatiza Lèry, são os espanhóis. Nesse sentido, os americanos, de cruéis sanguinários, passam a vítimas de uma crueldade ainda maior.

Tanto Lèry quanto Montaigne abominam métodos de execução dolorosos e o espetáculo da violência. Mesmo o abate de animais é por ambos considerado cruel, especialmente quando envolve alguma forma de entretenimento - como, por exemplo, em caçadas. ${ }^{12}$

Se, na Europa, a pena capital com frequência envolvia métodos longos e dolorosos, assim como formas elaboradas de tortura pre-mortem, os Tupinambá tinham por costume matar de um só golpe prisioneiros de guerra.

Ao descrever seus costumes, no décimo-quinto capítulo da Viagem à terra do Brasil, Lèry destaca a destreza dos verdugos e a rapidez da morte:

[...] Em seguida, para excitar ainda mais a indignação do inimigo, [o prisioneiro] leva as mãos à cabeça e exclama: "Eu não estou a fingir, fui, com efeito, valente e assaltei e venci os vossos pais e os comi". E assim continua até que seu adversário, prestes a matá-lo, exclama: "Agora estás em nosso poder e serás morto por mim e moqueado e devorado por todos".

\footnotetext{
11 Os três franceses (lean du Bourdel, Matthieu Verneuil e Pierre Bourdon) ficariam conhecidos como mártires da Guanabara, ou primeiros mártires protestantes nas Américas. Sua confissão de fé foi transcrita no martirológio de Jean Crespin (Recueil des martyrs. Cenebra: ]ean Crespin, 1564, pp. 340-389 para todo o episódio, e pp. 367-376 para a confissão). Sua tradução ao português pode ser consultada online em: http://www. ipci.org.br/arquivos/olooyConfissao_de_Fe_da_Cuanabara.pdf (acesso em abril de 2020). Os "mártires da Guanabara" são mencionados, ainda, em Les Vrais Pourtraits des Hommes illustres en pieté et doctrine, de Théodore de Bèze. Cenebra: Jean de Laon, 1581.

12 A respeito da crueldade animal ver BEIRNE, Piers. Confronting Animal Abuse. Law, Criminology and Human-Animal Relationships. Lanham/Boulder/Nova York/Toronto/Plymouth: Rowman \& Littlefield, 2009, p. 42 et seq.
} 
Mas tão resoluta quanto Atílio Régulo ao morrer pela República Romana, a vítima ainda responde: "Meus parentes me vingarão" [...] O selvagem encarregado da execução levanta então o tacape com ambas as mãos e desfecha tal pancada na cabeça do pobre prisioneiro que ele cai redondamente morto sem sequer mover braço ou perna. E dir-se-ia magarefe abatendo um boi. Em verdade muitas vezes as vítimas estrebucham no chão, mas isso por causa do sangue e nervos que se contraem. $\mathrm{O}$ executor costuma bater com tal destreza na testa ou na nuca que não se faz necessário repetir o golpe e nem a vítima perde muito sangue. ${ }^{13}$

A "facilidade" da morte é destacada igualmente, e de modo ainda mais enfático, pelo jesuíta José de Anchieta em uma carta de relação enviada em 1584:

Naturalmente [os nativos] são inclinados a matar, mas não são cruéis: porque ordinariamente nenhum tormento dão aos inimigos, porque se os não matam no conflito da guerra, depois tratam-nos muito bem, e contentam-se com Ihes quebrar a cabeça com um pau, que é morte muito fácil, porque às vezes os matam de uma pancada ou ao menos com ela perdem logo os sentidos. Se de alguma crueldade usam, ainda que raramente, é com o exemplo dos Portugueses e Franceses. ${ }^{14}$

O texto de Anchieta é ainda mais explícito no sentido de sublinhar a ausência de crueldade neste método de execução. Não há "tormento", isso é, tortura: as vítimas, pelo contrário, são bem tratadas até o momento em que recebem o único golpe mortal.

Em seu célebre ensaio "Dos Canibais", Montaigne formula reflexões sobre o modo de vida dos Tupinambá. Sua fonte, segundo ele próprio revela, era um colono que havia vivido "dez ou doze anos" na França Antártica. Além disso, já na parte final do ensaio, o humanista relata ter conversado pessoalmente - embora por intermédio de um intérprete que lhe pareceu muito incompetente com três Tupinambá que haviam viajado a Rouen.

Montaigne descreve alguns aspectos do seu modo de vida e exorta sua virtude guerreira; em seguida, relata o seu modo de executar inimigos capturados em batalha:

[...] Depois de terem dado por algum tempo bom trato aos prisioneiros, facilitando-lhes todas as comodidades ao alcance de sua imaginação, o chefe congrega seus amigos em uma grande assembleia; ata uma corda a um dos braços do prisioneiro, segurando na outra ponta, a alguns passos de distância, com medo de ser ferido, e dá o outro braço a segurar, da mesma forma, ao melhor de seus amigos; então ambos o abatem a golpes de espada, perante toda a assembleia. Feito isso, assam-no e comem-no entre todos e enviam alguns

\footnotetext{
13 LÉRY, Jean de. Viagem à terra do Brasil. Tradução de Sérgio Milliet. São Paulo: Martins, 1941, cap. XV.

14 ANCHIETA, José de. Informação do Brasil e se suas capitanias (1584). In: Cartas Jesuíticas. Rio de Janeiro: Academia Brasileira de Letras, 1933, v. 3, p. 329.
} 
pedaços aos amigos ausentes [...] Não me pesa acentuar o horror bárbaro que tal ação significa, mas sim que tanto condenemos suas faltas e tão cegos sejamos para as nossas. Penso que há mais barbárie em comer um homem vivo que morto, dilacerar com tormentos e martírios um corpo ainda cheio de vitalidade, assá-lo lentamente e arrojá-lo aos cães e aos porcos, que o mordem e martirizam (como vimos recentemente, e não lemos, entre vizinhos e concidadãos, e não entre antigos inimigos, e, o que é pior, sob pretexto de piedade e de religião) que em o assar e comer depois de morto. ${ }^{15}$

Montaigne, assim, estabelece um esquema comparativo segundo o qual o método de execução tupinambá parece-lhe menos bárbaro do que as espantosas torturas cometidas em solo europeu no âmbito das guerras de religião. Em seu ensaio sobre a crueldade, de fato, o humanista expressa claramente seu horror pelos tormentos e execuções dolorosas: "Quanto a mim, parece-me cruel, mesmo nos atos de justiça, tudo o que vai além da simples morte. E mais cruel ainda de nossa parte, a nós que deveríamos cuidar de fazer com que as almas abandonem a terra serenamente, o que se torna impossível se as submetemos a tormentos intoleráveis e atrozes suplícios."16

Essa inversão aparece com clareza também em imagens realizadas no período, nas quais, com frequência, é possível perceber, como vimos no exemplo da Ecclesiae Anglicanae Trophaea, um trânsito de fórmulas, ou códigos visuais, entre os campos dos martirológios, dos tratados legais nos quais se representam modos de punição e tortura pre-mortem, e da representação de povos americanos. Na primeira pagina do panfleto holandês "Espelho dos espanhóis e aragoneses" observa-se um exemplo significativo dessa inversão e, ao mesmo tempo, da migração de códigos visuais entre distintos gêneros discursivos e visuais [Figura 6]: na parte superior da gravura, duas evocações de massacres cometidos por espanhóis em vilarejos holandeses flanqueiam um espelho no qual um soldado espanhol aparece esfaqueando uma mulher e seu bebê. A cena à esquerda representa um soldado assando um membro humano em um espeto. Na parte inferior da imagem, pessoas de distintas partes do mundo - holandeses, turcos, Tupinambá - unem-se em terror diante das atrocidades cometidas pelos espanhóis. O canibalismo - uma das mais antigas metáforas da crueldade e barbárie -é, assim, deslocado, e os Tupinambá aparecem como vítimas, e não autores dos atos violentos.

A percepção da crueldade na Europa, assim, parece sofrer uma alteração profunda durante a primeira época moderna. O tradicional "outro" cruel do ocidente cristianizado, o qual se havia

15 MONTAICNE, Michel de. Dos Canibais. In: Ensaios, capítulo XXXI, livro 1. Tradução de ]. Brito Broca e Wilson Lousada (Clássicos Jackson). Disponível em: https://fabiomesquita.files.wordpress.com/2015/04/montaigne-michel-de-dos-canibais-ensaios.pdf. Acesso em: 24 abr. 2020. 16 Idem. Ensaios. Tradução de Sérgio Millet. São Paulo: Abril Cultural, 1984. 


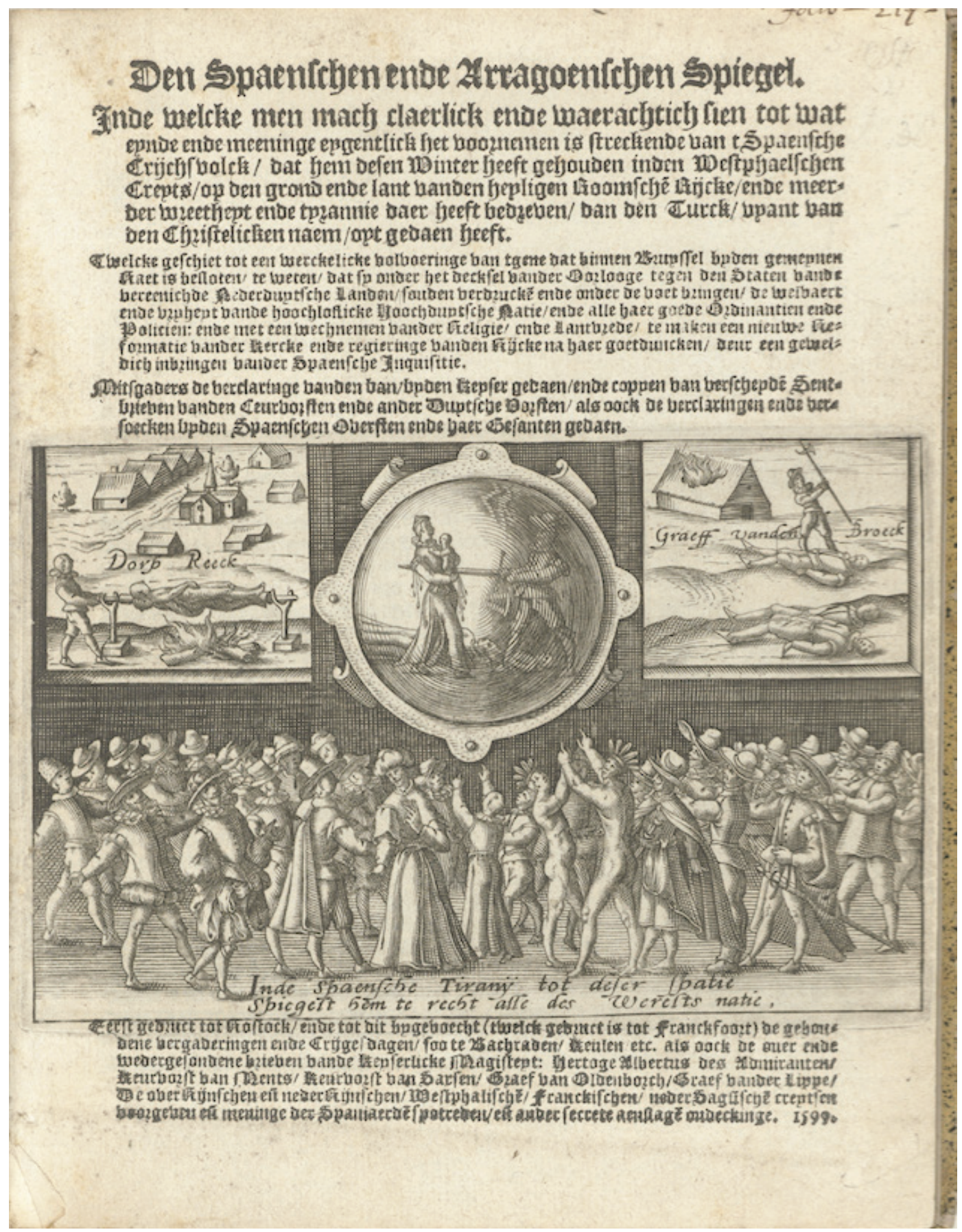

[Figura 6] Autor anônimo: Primeira página do panfleto "Den Spaenschen ende Arragoenschen Spiegel" [...]. Frankfurt, 1599. 
constituído a partir de uma multifacetada linhagem entremeando pagãos, muçulmanos, turcos, vikings, mongóis e, mais recentemente, americanos nativos - deixa de servir como critério absoluto, e, embora atitudes associadas a esses povos possam ainda surgir, tanto visual quanto retoricamente, como critério comparativo, a crueldade passa a ser uma categoria potencialmente atribuível também a membros da própria nação e religião. Para Montaigne, de fato, nem na distância temporal dos antigos romanos ou geográfica dos Tupinambá é possível encontrar exemplos tão terríveis de crueldade quanto os que viu, com seus próprios olhos, em seu país e tempo:

Vivo em uma época em que, por causa de nossas guerras civis, abundam os exemplos de incrível crueldade. Não vejo na história antiga nada pior do que os fatos dessa natureza, que se verificam diariamente e aos quais não me acostumo. Mal podia eu conceber, antes de o ver, que existissem pessoas capazes de matar pelo simples prazer de matar; pessoas que esquartejam o próximo, inventam engenhosos e desconhecidos suplícios e novos gêneros de assassínios, sem ser movidos nem pelo ódio, nem pela cobiça, no intuito único de assistir ao espetáculo dos gestos, das contorções lamentáveis, dos gemidos, dos gritos angustiados de um homem que agoniza entre torturas. É o último grau a que pode atingir a crueldade. ${ }^{17}$

17 Idem. Da Crueldade, 5. In: MONTAIGNE, op. cit., 1984. 
Referências Bibliográficas:

ANCHIETA, José de. Informação do Brasil e se suas capitanias (1584). In: Cartas Jesuíticas. Rio de Janeiro: Academia Brasileira de Letras, 1933, v. 3.

BARAZ, Daniel. Medieval Cruelty. Changing Perceptions, Late Antiquity to the Early Modern Period. Ithaca e Londres: Cornell University Press, 2003.

BEIRNE, Piers. Confronting Animal Abuse. Law, Criminology and Human-Animal Relationships. Lanham/Boulder/ Nova York/Toronto/Plymouth: Rowman \& Littlefield, 2009.

BELLAMY, John. The Tudor Law of Treason. Nova York: Routledge 1979.

CASAS, Bartolomé de las. Brevísima Relación de la Destrucción de las Indias. Alayor: textos.info, 2016. Disponível em: https://www.textos.info/fray-bartolome-de-las-casas/brevisima-relacion-de-la-destruccion-de-las-indias/descargar-pdf. Acesso em: 24 abr. 2020.

FOUCAULT, Michel. Surveiller et Punir: Naissance de la Prison. Paris: Gallimard, 1975.

KILROY, Gerard. Edmund Campion. A Scholarly Life. Farnham: Ashgate, 2015.

KNECHT, Robert. The French Religious Wars, 1562-1598. Oxford: Osprey Publishing, 2002.

KOCH, Alexander; BRIERLEY, Chris; MASLIN, Mark; LEWIS, Simon. Earth System Impacts of the European Arrival and Great Dying in the Americas after 1492. In: Quaternary Science Reviews, v. 207, 2019.

LÉRY, Jean de. Viagem à terra do Brasil. Tradução de Sérgio Milliet. São Paulo: Martins, 1941.

MONTAIGNE, Michel de. Ensaios. Tradução de Sérgio Millet. São Paulo: Abril Cultural, 1984.

MONTAIGNE, Michel de. Ensaios, capítulo XXXI, livro 1. Tradução de ]. Brito Broca e Wilson Lousada (Clássicos Jackson).

SPIERENBURG, Pieter. The Body and the State: Early Modern Europe. In: MORRIS, Norval Morris; ROTHMAN, David J. (orgs.). The Oxford History of the Prison: The Practice of Punishment in Western Society. Oxford University Press: 1995.

VILLAMIZAR, Carlos Arturo Salamanca. Religión, política y espectáculo: narrativas del martirio en la primera modernidad. In: Anales del Instituto de Investigaciones Estéticas, XXXVIII, v. 109, 2016.

WANDEL, Lee Palmer. The Eucharist in the Reformation. Incarnation and Liturgy. Cambridge: Cambridge University Press, 2006. 